\title{
PENERAPAN TEKNOLOGI PENGEMASAN DAN INOVASI PRODUK UNTUK MENINGKATKAN MUTU PRODUK PADA INDUSTRI KECIL MENENGAH BERBASIS OLAHAN PANGAN DI DESA CIKUDA KECAMATAN JATINANGOR KABUPATEN SUMEDANG
}

\author{
Selly Harnesa Putri, Irfan Ardiansah, dan Devi Maulida Rahmah
}

Lecturer at Department of Agro-Industrial Technology

Faculty of Agro-Industrial Technology

Email: selly.h.putri@unpad.ac.id

\begin{abstract}
ABSTRAK
Desa Cikuda merupakan desa yang bersebelahan dengan kampus Unpad Jatinangor berjarak sekitar 2,7 KM. Kurang sejahteranya masyarakat secara mandiri ditambah dengan jumlah angka pengangguran memunculkan peluang baru untuk beralih kepada pembentukan industry rumah tangga. Keberadaannya mampu memberikan ruang bagi banyak orang untuk tidak tergantung pada kerasnya persaingan dunia kerja. Permasalahan yang terdapat pada industry rumah tangga di desa tersebut adalah kualitas produk yang masih rendah, serta penampilan produk yang kurang menarik sehingga tidak berdampak pada kesejahteraan pelaku usaha. Perbaikan mutu produk dapat melalui penerapan teknologi pengemasan dan inovasi produk. Dengan adanya transfer pengetahuan pada masyarakat yang menjadi mitra dalam program ini yaitu pelaku IKM olahan pangan Desa Cikuda dapat menerapkan teknologi pengemasan dan inovasi produk, serta mendukung program pemerintah dalam meningkatkan perekonomian masyarakat.
\end{abstract}

Kata kunci: teknologi pengemasan, inovasi produk, IKM

\begin{abstract}
Cikuda is a village near to Unpad campus in Jatinangor is about $2.7 \mathrm{KM}$. The lack of prosperity of the community independently coupled with the number of unemployed numbers raises new opportunities to shift to the establishment of the household industry. Its existence is able to provide space for many people not to depend on the rigors of the work world competition. Problems in the household industry is the product quality was still low, and the appearance of the product that is less attractive so as not to affect the welfare of business actors. Improvement of product quality can be through application of packaging technology and product innovation. Transfer knowledge to the community that is a partner in this program is the perpetrator of IKM at Cikuda can apply packaging technology and product innovation, and support the government program in improving the economy of the community.
\end{abstract}

Keywords: packaging technology, product innovation, Small Medium Enterprise 


\section{PENDAHULUAN}

Industri rumah tangga merupakan sektor terpenting dalam menggerakkan roda perekonomian masyarakat secara mandiri. Keberadaannya mampu memberikan ruang bagi banyak orang untuk tidak tergantung pada kerasnya persaingan dunia kerja. Oleh karenanya pengembangan industri rumah tangga atau biasa dikenal dengan Usaha Mikro, Kecil, dan Menenngah (UMKM) menjadi harapan untuk mengatasi jumlah pengangguran dan mensejahterakan masyarakat secara mandiri baik di daerah maupun di kota besar.

Aktifitas usaha dalam bentuk industri kecil menengah juga terdapat di Desa Cikuda Kec Jatinangor.IKM olahan pangan yang mendominasi aktifitas usaha dalam IKM, seperti aneka keripik serta olahan bahan hasil pertanian seperti olahan singkong dan olahan jagung.Permasalahan yang terdapat didalam IKM di kedua desa tersebut adalah kualitas produk yang masih rendah,serta penampilan produk yang siap dipasarkan yang kurang menarik sehingga tidak berdampak pada kesejahteraan pelaku IKM.Permasalahan yang dihadapi oleh IKM tersebut sekaligus menjadi potensi yang besar bagi peningkatan perekonomian masyarakat, ketika IKM mampu memberikan keuntungan finansial melalui perbaikan kualitas produk yang dihasilkan.Perbaikan mutu produk IKM dapat melalui penerapan teknologi pengemasan dan inovasi produk. Penerapan teknologi pengemasan, selain akan meningkatkan harga jual produk, juga akan memperluas segmentasi pasar. Begitupula dengan inovasi produk. Inovasi produk dapat berupa pengembangan produk turunan yang lebih bervariasi, sehingga banyak pilihan produk yang dapat ditawarkan ke pasaran.

Kegiatan Pengabdian ini akan difokuskan pada Pelaku IKM olahan pangan yang ada di Desa Cikuda dengan tujuan peningkatan mutu produk IKM melalui penerapan teknologi pengemasan dan inovasi produk. Hal ini dilakukan agar kegiatan pengabdian ini memiliki impact yang signifikan bagi pengembangan IKM di kawasan tersebut. Kegiatan ini juga selaras dengan program 10 common Goals

Jawabaratdimana salah satu programnya adalah peningkatan perekonomian masyarakat melalui sector pertanian dan non pertanian.

\section{METODE PENELITIAN}

Metode pelaksanaan menggunakan metode perancangan metode rekayasa sosial yaitu merancang tahapan praktis dalam pendampingan IKM olahan dalam peningkatan mutu poduk yang telah mereka tekuni selama ini. Agar program ini dapat dilaksanakan sesuai target luaran yang akan dicapai, maka metode pelaksanaan program yang akan diterapkan adalah sebagai berikut

1. Sosialisasi kepada pejabat desa terkait program; hal ini dimaksudkan untuk menggalang kekuatan agar dalam pelaksaan program ini tidak hanya didukung oleh satu pihak saja, yaitu kampus sebagai pelaksana program, namun juga ada partisipasi aktif warga setempat dalam pelaksanaannya

2. Pemetaan Masalah dan Potensi Perekonomian Desa dan kondisi IKM

a. Mengidentifikasi kondisi IKM yang ada di Desa melalui observasi dan survey ke IKM yang ada di Desa

b. FGD dengan pelaku IKM untuk mengetahui akar masalah dan solusi yang bisa dilakukan

3. Pelatihan Inovasi Produk

a. Pengenalan beberapa metode yang dilakukan dalam inovasi produk

b. Pengenalan inovasi produk yang dapat dilakukan untuk industri makanan olahan.

c. Mengenalkan beberapa contoh inovasi produk yang bisa dilakukan dalam meningkatkan harga jual dan sasaran konsumen, seperti peningkatan kualitas produk, kualitas kemasan, sistem pemasaran, dll.

4. Pelatihan Penerapan teknologi Pengemasan

a. Pengenalan macam-macam teknologi pengemasan dan kelebihan nya

b. Melakukan pelatihan dalam proses pengemasan dengan salah satu metode

5. Penerapan pada IKM yang terpilih

6. Pendampingan dan pembinaan anggota

\section{HASIL DAN PEMBAHASAN}

Diskusi Permasalahan Mitra.

Menindaklanjuti hasil survey maka tim pelaksana melakukan diskusi dengan mitra dan bersepakat untuk melakukan kegiatan pembinaan IKM olahan pangan berupa pendalaman teknologi kemassan dan inovasi produk dengan peningkatan nilai tambah, 
Kemudian dilanjutkan dengan penentuan jadwal pelaksanaan kegiatan, pengarahan, dan bimbingan seperti yang disajikan pada Gambar 1.

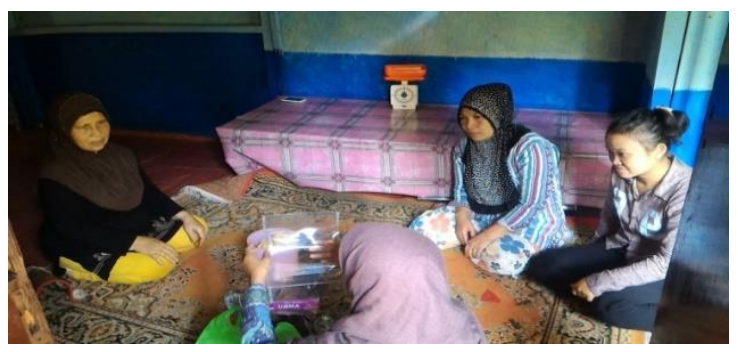

Gambar 1.

Diskusi permasaalahan yang dihadapi oleh mitra

\section{Pengiriman bahan kemasan, label} kemasan dan sealer. Penyerahann bahan kemasan yang lebih ergonomis, menarik dan mudah diguanakan serta label kemasanyang telah di design sehingga dengan kombinasi pembaruan kemasan dan label tersebut dapat meningkatkan nilai tambah produk yang lebih tinggi, kemudian diberangkatkan ke lokasi mitra untuk dilakukan aplikasi terhadap alat tersebut dilapangan (gambar 2)
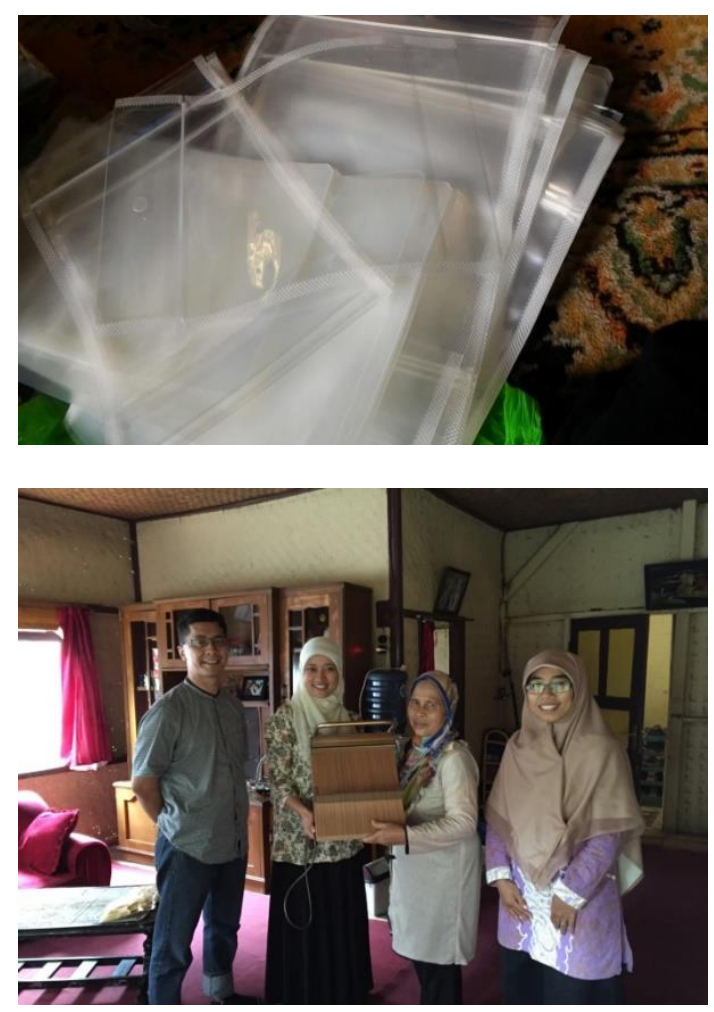

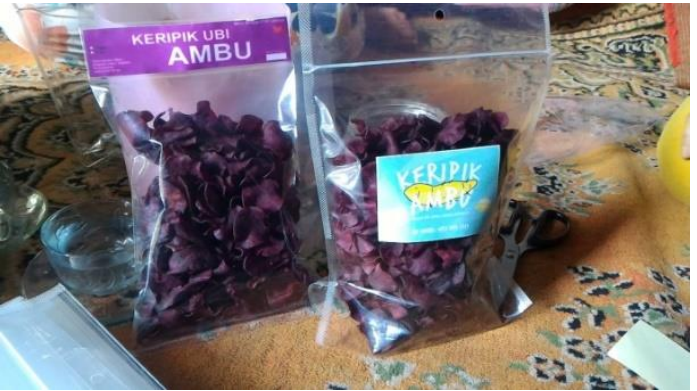

Gambar 2.

Bahan kemasan, label dan kombinasi pada produk.

\section{Sosialisasi dan Pendampingan} Pelatihan Teknologi Kemasan dan inovasi produk. Pelaksanaan sosialisasi dan pendampingan dilakukan pada hari Kamis, 21 Juli 2016 di desa Cikuda Kecamatan Jatinangor yang dihadiri oleh ketua dan anggota Kelompok olahan pangan. Materi sosialisasi disampaikan dengan cara praktek dan diskusi.

Indikator Keberhasilan Program. Bertitik tolak pada kondisi sebelum dan sesudah PPM Prioritas, hasil evaluasi menunjukkan bahwa adanya peningkatan pengetahuan dan keterampilan peserta mengenai alternative teknologi pengemasan dalam meningkatkan penjualan produk, peningkatan manajemen kelompok, motivasi menjalankan usaha pengolahan pangan dengan nilai tambah tinggi.
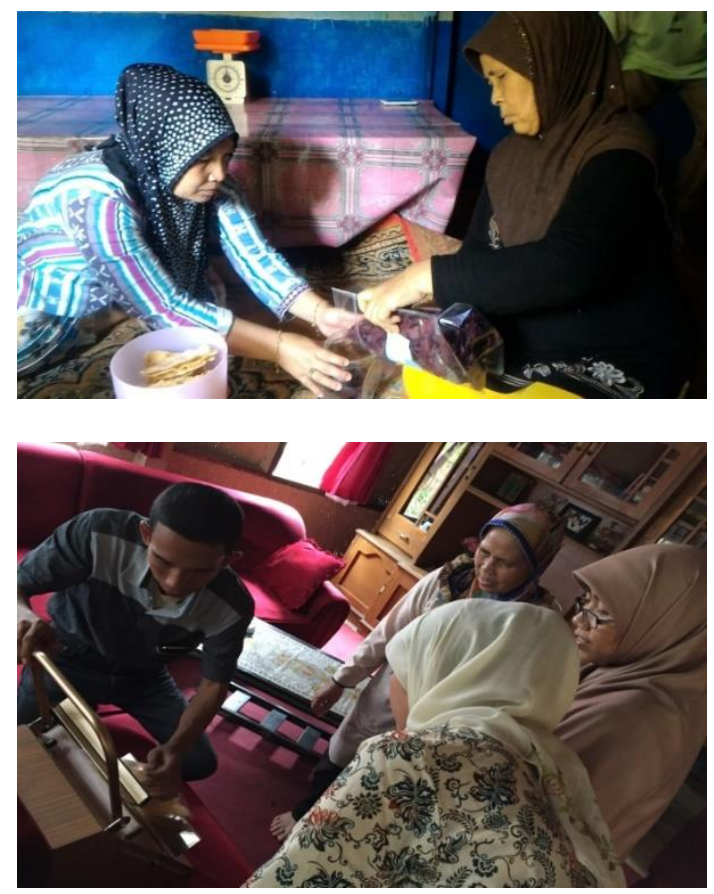


\section{Gambar 3.}

Sosialisasi dan pendampingan.

Proses pendampingan teknologi kemasan telah berjalan dengan baik yang ditandai dengan pemahaman masyarakat mengenai tahapan proses penignkatan nilai tambah melalui perbaikan kemasan dan label yang lebih "eye cathcing" dan ergonomis. Peserta yang hadir sangat antusias ketika mengikuti seluruh kegiatan sosialisasi dan pendampingan penerapan teknologi pengemasan dan inovasi produk pangan olahan. Hal ini dibuktikan dengan banyaknya pertanyaan yang dilontarkan kepada tim PPM Prioritas dan diakhir dengan diskusi diakhir pembimbingan.

Pada bagian akhir kegiatan, ketua kelompok IKM memberikan kesan, pesan dan ucapan terima kasih atas kegiatan ini dengan harapan kegiatan ini dapat berkesinambungan untuk tahun depan karena kegiatan ini sangat berkontribusi terhadap pembangunan perekonomian dan kesejahteraan masyarakat.

\section{KESIMPULAN}

Dari pelaksanaan kegiatan yang dilakukan dapat diambil kesimpulan sebagai berikut :

1. kegiatan transfer teknologi pengemasan dan inovasi produk berjalan dengan baik

2. Kegiatan pengabdian kepada masyarakat di khalayak sasaran berjalan dengan baik dengan respon yang baik juga, hal ini dibuktikan dengan partisipasi aktif peserta dalam semua materi yang diberikan.

3. Adanya peningkatan pengetahuan dan keterampilan dalam proes pengemasan dalam menghasilkan produk olahan pangan yang bernilai tambah

\section{DAFTAR PUSTAKA}

Cenadi. 2000. Peranan Desain Kemasan dalam Dunia Pemasaran. Jurnal Nirmala Vol 2, No 1. Januari 2000:92-103

Coles, Richard, Mc Dowell. 2003. Food Packaging Technology. CRC Press. Marsh, Kenneth. 2007. Food Packaging Roles, Material, and Enviromental Issues. Journal of Food Science Vol 72, no 03 